\title{
De la nueva trova al rap cubano: resistencia y negociaciōn de Orishas
}

\section{From nueva trova to Cuban Rap: Strategies of Resistance and Negotiation in the Group Orishas}

LARA I. LÓPEZ DE Jesús / larailopez@gmail.com Universidad de Puerto Rico, Río Piedras

\section{Resumen / Abstract}

Este artículo parte del desarrollo de dos preguntas principales: ¿cómo el grupo Orishas ha reinventado los términos en los que se piensa y expresa la nación? Y ¿cómo se entiende una manifestación cultural afrocubana que aparece en un contexto en el que el gobierno cubano tomó el rol de "proteger" del mercado la autonomía de sus culturas expresivas? Propongo que las estrategias de negociación y resistencia de Orishas, aunque son propias no son nuevas, y se relacionan con otros fenómenos sonoros fundamentales en la conformación del imaginario nacional cubano, como la nueva trova y la timba. Además de describir la relación que entabla el rap cubano con esos dos fenómenos, me enfoco principalmente en las maneras en que Orishas se apropia de los imaginarios transnacionales con el fin de enmarcar demandas políticas y estrategias locales.

\section{Palabras clave}

Cultura cubana, música cubana, Periodo Especial, imaginarios transnacionales, cultura afrocubana.
This article addresses two principal questions: How has the group Orishas reinvented the terms in which the idea of nation is discussed and expressed? How can we interpret Afro-Cuban cultural expression within a (national) context in which the Cuban government set out to "protect" the autonomy of it cultural expression from the (global) market? I propose that the negotiation and resistance strategies employed by the Orishas, although their own, are not in fact new, and relate to other fundamental sound phenomena in the Cuban collective imagination, such as nueva trova and timba. In addition to describing the relationship of Cuban rap to these two phenomena, I focus on the ways in which the Orishas lay claim to transnational imaginaries with the purpose of defining political demands and local strategies.

\section{KeYWORDS}

Afro-Cuban Culture, Cuban Culture, Transnational Imaginaries, Cuban Music, Special Period. 


\title{
De la nouvelle trova au rap cubain: résistance et négociation du groupe Orishas
}

\section{Van de nueva trova naar de Cubaanse rap: verzet en onderhandeling van de groep Orishas}

\author{
LARA I. LÓPEZ DE Jesús / larailopez@gmail.com \\ Universidad de Puerto Rico, Río Piedras
}

\begin{abstract}
Cet article s'appuie sur deux questions principales: comment le groupe Orishas a-t-il réinventé la façon de penser et d'exprimer la nation ? Comment est interprétée une manifestation culturelle afro-cubaine dans un contexte où le gouvernement cubain vise à "protéger» l'autonomie des expressions culturelles de l'emprise du marché ? Je suggère que les stratégies de négociation et de résistance d'Orishas, bien qu'originales, ne sont pas nouvelles, et doivent être rattachées à d'autres phénomènes sonores fondamentaux dans le développement de l'imaginaire national cubain, comme la nouvelle trova et la timba. Au-delà de la description de la relation entre le rap cubain et ces deux phénomènes, je me centre principalement sur les formes d'appropriation, par Orishas, des nouveaux imaginaires transnationaux, afin de porter des demandes politiques et des stratégies locales.
\end{abstract}

Résumé / Samenvatting

\section{Mots-Clés}

Culture afrocubaine, culture cubaine, imaginaires transnationaux, musique cubaine, période spéciale.
In dit artikel worden als uitgangspunt twee centrale vragen gesteld: Hoe heeft de muziekgroep Orishas een nieuwe manier van denken en expressie, een nieuwe verbeelding, van het Cubaanse volk uitgevonden? En hoe moeten we een Afrocubaans cultureel verschijnsel zien in het kader van een Cubaanse regering die de rol op zich heeft genomen van "beschermer" van de autonomie van haar culturele uitdrukkingsvormen tegen de marktwerking? Naar mijn idee zijn de onderhandelings- en verzetsstrategieën van de Orishas wel van henzelf, maar ze zijn niet nieuw. Ze zijn gerelateerd aan andere essentiële welluidende expressieve manifestaties die de nationale Cubaanse culturele verbeelding vorm gegeven hebben, zoals de nueva trova en de timba. Naast een beschrijving van de relatie die de Cubaanse rapmuziek legt met deze twee muziekvormen, concentreer ik me vooral op de manier waarop de groep Orishas zich een transnationale culturele verbeelding toe-eigent met als doel plaatselijke politieke eisen en strategieën in te kaderen.

\section{SLeUtelWOORDEN}

Afrocubaanse cultuur, Cubaanse cultuur, transnationale verbeelding, Cubaanse muziek, speciaal tijdperk 
¿Qué cosa no es comercial?

Todo pasa a ser producto, porque tienes que vender tu música, expandirla y la única forma es con el comercio.

HiRAM RUZZO RIVERÍ

Aunque la gente lo quiera llamar comercial, supercomercial, o extracomercial, lo que sea, si Orishas está pega'o es porque somos cubanos y hacemos un trabajo meritorio. $Y$ esto va a abrir las puertas a muchos raperos undergrounds y a otros comerciales. Eso es lo importante.

Yotuel ROMERO

La música se ha estancado.

Vivimos de recuerdos. Lo moderno no existe ahora mismo. Entre mierda y nuevo, se ha hecho demasiado. Hay que inventar instrumentos nuevos, agregarle dos notas a las siete que hay. Y, como dicen en el boxeo, pesar más de 91 kilos para que apuesten por ti.

Roldán González

\section{Introducciōn}

Difusión y éxito de un producto musical

Marcados por el movimiento y el viaje, los integrantes originales de Orishas coincidieron en París, ciudad que les permitió fundar hacia fines de la década de los noventa este grupo de rap cubano que se mantuvo activo hasta 2010. Roldán González Rivero desde París, Hiram Ruzzo Riverí Medina desde Milán y Yotuel Guerrero Romero Manzanares desde Madrid -junto con Liván Flaco Pro Núñez Alemán y el productor francés Niko Noki-1 produjeron su primer disco,

${ }^{1}$ La trayectoria musical de dos de sus integrantes, Ruzzo y Yotuel, se remonta a cuando vivían en Cuba, ya que ambos formaron parte de una de las primeras bandas de hip hop en la isla, el grupo Amenaza. Ruzzo y Yotuel, además, aprendieron música 
A lo cubano, en mayo de 1999; recibió una excelente crítica de la prensa europea y logró entrar en poco tiempo al mercado latinoamericano, brasileño, sudafricano, canadiense y estadounidense. ${ }^{2}$

Sin embargo, el éxito de la banda fue en un principio debatido. Algunos músicos y académicos cuestionaron tanto el valor del rap en general como la formación musical de algunos de sus integrantes. Otros críticos con tendencias más nacionalistas entendieron que el rap era una música que había que evitar en Cuba, ya que el movimiento (de hip hop específicamente) se había originado en Estados Unidos hacia finales de los años sesenta. Dentro del

de forma no escolarizada. Roldán era el único músico "profesional" de la banda, pues estudió guitarra clásica y canto coral en el Conservatorio, y trabajó en varias agrupaciones cubanas de música tradicional, como Rico Son. Amenaza llegó a ganar el primer premio en la tercera edición semiclandestina de un festival de rap cubano. La presidenta de la Asociación de Solidaridad con el Pueblo Cubano (ADHESIF) escuchó el trabajo de ese grupo y se hizo responsable de llevarlos a Francia para un intercambio cultural a través del rap, que estuvo mediado por la importante Asociación Hermanos Saíz (AHS) de Cuba. Amenaza tuvo problemas con la ADHESIF, lo que concluyó en que dejaron el trato que tenían y se quedaron en Francia. En su página oficial virtual, mientras estuvieron activos como grupo (http://www.orishasthebest.com), los integrantes narraron sus historias y cómo pudieron seguir sus carreras musicales.

${ }^{2}$ Orishas produjo cinco discos. Al primero, A lo cubano, le siguieron los compactos Emigrante y El kilo. Trabajaron también en un proyecto Ilamado Cuban Beats All Star. Emigrante lo grabaron con la casa disquera EMI. Este disco es más melódico que el primero, que se caracteriza por ser más enérgico y rítmico, y los temas de Emigrante, en comparación con los del primer disco, son considerados más internacionales. $\mathrm{Al}$ preguntarles al respecto los integrantes comentaron en varias entrevistas que la internacionalización de los temas fue resultado del impacto de los viajes que realizaron por el mundo y de las experiencias dentro del sistema de mercado musical, capitalista y global. Emigrante salió en 2002 y fue promocionado en una gira por diez países. En 2003, la revista Time incluyó a Orishas en su lista de las diez bandas más importantes fuera de Estados Unidos. Asimismo, el grupo fue nominado al Grammy en la categoría de Mejor Álbum de Rock-Alternativo Latino, ganó el premio al Mejor Disco Hip HopRap por su segundo larga duración Emigrante y el premio al Mejor Disco de Hip Hop Internacional concedido por The Source. El tercer disco salió a la venta en Europa en febrero de 2005. Con el nombre de El kilo, que significa céntimo de la moneda nacional, este compacto obtuvo una nominación a los Grammy Latinos 2005 en la categoría de Mejor Álbum de Música Urbana. Cuban Beats All Stars grabó los temas que integraron su primer disco y que mezclan la tradición cubana, la música de raíz, con sonidos electrónicos y tribales. Además de canciones propias, mezclaron clásicos de la música tradicional cubana y de Latinoamérica con música electrónica. En 2007, Orishas recibió un Grammy junto al rapero puertorriqueño Calle. Estos datos refuerzan la idea de cómo el grupo logró penetrar el mercado internacional, especialmente el estadounidense. En 2014, Niko Noki, Roldán y Jon D Jon crearon el grupo La Cosa Nuestra. 
mismo movimiento rapero cubano, Orishas también fue criticado por haber negociado con las casas disqueras extranjeras y haberse alejado de la función social y estética que debía tener la música en una Cuba todavía considerada "revolucionaria". Empero, la música de la banda también logró llegar al público cubano. Esta se presentó varias veces en la isla, y reunió a miles de personas en sus conciertos. Una de las ocasiones más especiales fue su participación en el 2000 durante el espectáculo conmemorativo de la Revolución de 1959.

La página oficial de Orishas (http://www.orishasthebest. com) -que se mantuvo activa hasta que se separaron-, así como varias entrevistas, establecían que el grupo se autorreconoció como "producto" que sale de la calle, y sus integrantes expresaron haber encontrado la fórmula perfecta para el éxito: 50\% música autóctona cubana y 50 \% hip hop. Además, Ilegaron a comentar que uno de sus mayores logros había sido demostrar a Estados Unidos su presencia y poder musical, pues, según explicaban en su página web, entraron a la casa del monstruo, les presentaron su producto y los hicieron consumirlo. Con esta trayectoria es fácil notar el éxito comercial del grupo y su transformación en un producto musical mercadeable.

No obstante, y a pesar de su comercialización y éxito rápido, planteo que Orishas representa y narra, como texto de la cultura, discursos distintos que proyectan la complejidad de las relaciones que establece la música cubana con lo político, lo nacional y lo económico. La música y las letras de la agrupación no reflejan la realidad de forma inocente (por más que algunos críticos hayan querido verlo así). Tampoco debe decirse que su carrera fue manipulada totalmente por la industria cultural. Su mensaje se configura como un grito ameno que, a pesar de utilizar estereotipos cubanos gastados, juega hábilmente con los valores tanto revolucionarios como de la sociedad deconsumocapitalista, afirmandodemaneraconstantelaposición de la cultura cubana ante el mundo. 
De este modo, la trayectoria y el quehacer musical de Orishas también comentan agudamente sobre las tensiones, las contradicciones y los coqueteos históricos, económicos y culturales que se enredan en este peculiar junte musical. La producción discográfica del grupo atrapa al escucha en las redes de los diferentes discursos identitarios y musicales que manejan sus integrantes y, en el camino, presenta sus estrategias de resistencia y negociación frente a las fuerzas políticas, económicas, nacionales y transnacionales contemporáneas. ¿Cómo entender, entonces, una manifestación cultural afrocubana que surge fuera de Cuba en un contexto histórico específico en el que, de hecho, las instituciones oficiales cubanas participaron activamente en el proyecto de proteger del mercado la autonomía de sus culturas expresivas? Propongo que las estrategias de negociación y resistencia de Orishas, aunque propias, no son nuevas y se vinculan con otros fenómenos sonoros fundamentales en la conformación del imaginario nacional cubano, como la nueva trova y la timba. Además de describir la relación que entabla el rap cubano con esos dos fenómenos, me enfoco sobre todo en las maneras en que el grupo se apropia de los imaginarios transnacionales con el fin de enmarcar demandas políticas y estrategias locales.

\section{De la nueva trova al rap cubano, cruzando por la timba}

En las páginas que siguen examinaré -utilizando algunas fuentes primarias y secundarias, páginas web y reseñas de los discos- las estrategias de negociación y resistencia de Orishas, para plantear que, aunque propias, no son nuevas y se relacionan de modo peculiar con otros fenómenos musicales fundamentales y fundadores del imaginario nacional cubano contemporáneo, como la nueva trova y la timba, principalmente. Ariel Fernández Díaz (2001), comentarista de prensa y editor de Movimiento (revista cubana oficial dedicada al rap que publicó su último número en febrero de 2014), explicó que el rap cubano navegaba "por las mismas aguas por las cuales navegó la trova en sus inicios, incomprendidos, censurados a pesar 
de portar la verdad en sus manos" (p. 7). Al concluir su comentario, Fernández Díaz enfatiza que los raperos hacen "revolución" con sus textos y "educan" con su poesía. Las tres palabras resaltadas, verdad, revolución y educación, vinculan el discurso de Fernández Díaz con la política cultural cubana dominante, una que persistía en afirmar que las expresiones culturales debían portar la verdad, como la concebía el metarrelato revolucionario, y que el objetivo debía ser la educación. En este sentido, los argumentos del analista -creyente en el poder musical y social del rap- reflejan la posición oficial de las instituciones del gobierno cubano hacia finales del siglo xx, que tendía a subordinar la producción artística a la revolución, y que reconocía que debía imperar una concepción didáctica y utilitaria de lo estético.

La nueva trova cubana surgió espontáneamente como producto, reflejo y recreación del pensamiento revolucionario, según ha reconocido Otero Garabís (2000). Es decir, participó de las posturas de la cultura oficial y expresó en un momento histórico específico el intento de "elevar" la calidad estética de la canción popular (a la vez que reafirmaba su compromiso social), buscando ser popular sin caer en la "normalización" promovida por la industria cultural. Al estudiar principalmente la música de Silvio Rodríguez, Otero Garabís señala que, desde una perspectiva cultural, la nueva trova se configuró como la conciliación entre el proyecto populista y el arte de vanguardia: síntesis entre el compromiso político y el estético.

Del surgimiento de la nueva trova a la aparición de la timba y el rap en el escenario musical cubano transcurrieron varias décadas. Sin embargo, fue durante la caída del bloque soviético hacia finales de los ochenta, el comienzo del Ilamado "Periodo Especial en tiempos de paz" y la crisis de los balseros que la cultura cubana se transformó vertiginosamente. Para enfrentar los problemas materiales graves que vivió el pueblo cubano, el gobierno llevó a cabo una serie de reformas económicas significativas, entre ellas el abandono de la industria del azúcar y el fortalecimiento del turismo. La expansión de este último provocó a su vez una propagación de la música 
popular bailable y la revitalización de la vida nocturna, sobre todo en La Habana. En este contexto los músicos comenzaron a ganar de nuevo una popularidad espectacular, entraron al país de manera agresiva las casas disqueras extranjeras y se volvió a difundir de forma sorprendente la música cubana alrededor del mundo. ${ }^{3}$

La vocación de síntesis cultural que propuso musicalmente la nueva trova ya no funciona en esta época. En los años noventa no es solo La Habana, sino la música popular cubana en general la que "no aguanta más" (como dice la letra de una de las canciones más famosas del grupo Los Van Van). Primero con la timba, y luego (o al mismo tiempo) con el rap, la música popular cubana cambia drásticamente.

La timba, además de mostrar el impacto que tuvo la crisis en la forma de actuar y sentir del pueblo cubano, presenta varios puntos de contacto significativos con la nueva trova. Perna (2005) reconoce el papel fundamental que representó la carrera artística de José Luis Cortés para el desarrollo de este movimiento sociomusical. La idea musical de Cortés, fundador del grupo NG La Banda, era crear un tipo de música arraigada a la vida del barrio que mezclara el jazz, la salsa, la rumba y el rap, y que empleara arreglos musicales ejecutados por músicos virtuosos que combinarían las aspiraciones artísticas con la popularidad. En un primer acercamiento esta idea se asemeja a la nueva trova, en especial al proyecto de Silvio Rodríguez. Es decir, al igual que la nueva trova, la timba expresó el deseo de enlazar la tradición con el experimento. Empero, la fusión de la nueva trova fue mayormente entre la poesía (con la creación de líricas elaboradas) y el discurso político, mientras que la de la timba fue entre la poética de la marginalidad, la actitud hedonística

${ }^{3}$ En 1997, Cuba firmó el Convenio de Berna, acuerdo para actualizar sus derechos de propiedad intelectual a las normas internacionales. El mismo año, la Sociedad General de Autores y Escritores (SGAE) de España abrió una sucursal en La Habana. Este dato es sumamente importante para el boom musical que le siguió, que influyó tanto al rap como a otros géneros musicales que podrían promover turismo. En ese momento se comienza a ver dos tipos de música en Cuba: una hecha para exportación y otra para consumo dentro de la isla. De aquí surge, en parte, la relevancia de Orishas. 
del barrio afrocubano del Periodo Especial y el coqueteo con las disqueras extranjeras. Para Perna, el éxito de la timba, en concreto la producida por Cortés, tiene que ver con su capacidad de negociar entre tensiones opuestas, pues la timba navegó entre la música arte y la cultura del barrio, la economía legal y la subterránea.

Como todo movimiento musical popular importante, la timba también Ilamó la atención del gobierno cubano, el cual entre 1993 y 1997 apoyó su desarrollo y, mediante distintas instituciones (cada una con diversos intereses, como la Agencia Cubana de Rap, la Asociación Hermanos Saíz -AHs- y el Instituto Cubano de la Música, entre otras), autorizó a los timberos a negociar con compañías extranjeras y realizar giras internacionales. Grupos como NG La Banda, Los Van Van y La Charanga Habanera mostraron en esa época su habilidad para entrar en los medios controlados por el gobierno, ingresando asimismo en los medios de comunicación de masas para alcanzar acceso económico y difusión en otras partes del mundo. Lo significativo es que, en el proceso, estos grupos lograron subvertir las relaciones de poder entre extranjeros y locales, pues su música abrió un espacio ambiguo que permitió adoptar explícitamente algunos símbolos y comportamientos "occidentales" vinculados, por ejemplo, con las dinámicas de consumo que exhiben otras industrias (como el cine, los deportes y la moda), mientras que a la vez se presentó, según analiza Perna, como un poderoso ritual de resistencia que generó distintos significados y alternativas frente a los discursos dominantes.

Los mensajes de muchas líricas de la timba celebran la vida extravagante y representan el sueño de los jóvenes pobres desilusionados con las promesas de la revolución. Muchas canciones de timba, además, expresaban abiertamente los "beneficios" del individualismo y los valores consumistas. Sin embargo, a mitad de los noventa cambia la recepción que en Cuba se tiene sobre esta manera de hacer música pues la prensa comenzó un ataque sistemático hacia la música bailable en general, no tanto por sus líricas sino por "traicionar" el espíritu de la música cubana y porque sus músicos se erguían como 
individuos devotos al culto del éxito y del dinero (así lo muestra, por ejemplo, la carrera del timbero Manolín, conocido como el Médico de la Salsa). En 1997 se toman medidas fuertes contra el crimen y la economía informal, y en el proceso se llevaron a cabo muchas operaciones contra discotecas y lugares nocturnos. De este modo, los timberos se convirtieron, para una parte del sector oficial, en fuerzas potencialmente antirrevolucionarias y neocapitalistas.

La historia del rap en Cuba tiene puntos de contacto con la de la timba y comparte algunas semejanzas notables en cuanto a sus estrategias de negociación con varios sectores del mercado y su resistencia hacia algunos discursos provenientes de las esferas de poder, como el gobierno y la industria cultural. No obstante, ambas prácticas han recorrido caminos distintos, comenzando por su origen, pues el discurso textual del rap forma parte del amplio movimiento cultural conocido como hip hop, el que, según Eklund Koza (1999), representa la innovación popular más significativa de Estados Unidos en los últimos 40 años más o menos. En cualquier ciudad del orbe el rap empezó como un género producido principalmente por y para adolescentes negros urbanos y pobres de la clase trabajadora. Aunque en cada espacio cultural el rap ha cobrado sus singularidades, los ejecutantes de este género musical y la música en sí comparten ciertas características en muchas partes del mundo, lo que hace que haya trascendido las fronteras nacionales en varios sentidos.

En Cuba, al igual que con la timba, muchos prejuicios giraron en torno a esta forma de hacer música. Primero por venir de Estados Unidos, según se mencionó, pues se le percibía como música del enemigo. ${ }^{4}$ Además, se le cuestionaba su valor musical y se le

${ }^{4}$ Un hecho relevante que acertadamente trabaja Fernandes (2003) tiene que ver con la relación entre el rap cubano y el estadounidense, pero no por la asociación del primero con símbolos estadounidenses de ostentación y consumo, sino por una red Ilamada Black August Hip Hop Collective, establecida en 1970 en el sistema de prisiones californiano, cuyo fin era unir el movimiento de hip hop en el mundo y aumentar la resistencia en América. Estos flujos transnacionales basados en la raza se alejan del flujo cultural relacionado con la industria de música popular (Fernandes, 2003, p. 581). 
consideraba una expresión superficial, que se fundamentaba en la obscenidad y en la ofensa, y que promovía la xenofobia. Como la timba, el rap cubano utiliza un lenguaje callejero y duro para narrar las situaciones y realidades que acontecen en el barrio. Muchas de las líricas raperas aluden al bajo mundo y abordan directamente cuestiones de raza y clase. También como en la timba, los símbolos lujosos que ostentan ciertos raperos (cadenas, joyas y carros) representan éxito y riqueza en una primera lectura, pero connotan otros significados más complejos al ser estudiados a fondo.

El rap en Cuba es un movimiento cultural que se ha generalizado y ha trascendido las fronteras de la isla. Tiene presencia televisiva y radial, y se ha mezclado con una gran variedad de géneros musicales, entre ellos la timba. Al igual que esta, el rap cubano pasó de constituir un fenómeno local a ser apoyado por el gobierno con conexiones transnacionales. ${ }^{5}$ Desde 1991 se dio un proceso de institucionalización y comercialización del rap muy interesante en el que participaron los integrantes del grupo Orishas. A falta de un movimiento político organizado u otra manera de asociación política permitida, el rap proveyó, según ha explicado Fernandes (2003, p. 577), una forma de expresión política alterna y de resistencia cultural. Al fundamentarse en entrevistas realizadas a los raperos cubanos (y sinquerercaeren reduccionismosoesencialismos), Fernandes establece que en Cuba existían, aunque de manera problemática,

${ }^{5}$ Desde 1990 se organizaban conciertos de rap en peñas en las casas de cultura, existían los programas de radio La esquina del rap y Señales, y había un espacio en la televisión que promovía artistas de rap internacional. En 1990, la AHS y la Unión de Jóvenes Comunistas (UJC), agrupaciones oficiales, instauraron un espacio para el rap en La Piragua, escenario en el malecón. El promotor del rap cubano Rodolfo Rensoli desempeñó un rol importante en la difusión de este género en Cuba. Él creó la asociación de raperos autónoma Ilamada Grupo Uno, que organizó el primer festival del rap a mediados de la década de los noventa. Desde entonces se celebraban festivales anuales en el Anfiteatro Alamar, auspiciados por la AHS y la Agencia Cubana de Rap, que están regidas por el Instituto Cubano de la Música (ICM)/Ministerio de Cultura, institución que a su vez pertenece al Centro Nacional de Música del ICM. Hoy día la Agencia Cubana de Rap hace un evento anual en La Habana, pero no tiene la magnitud de los que realizó con la AHS y otros órganos institucionales desde mediados de los noventa hasta 2007 aproximadamente. La AHS es la rama del entretenimiento para la UJC, órgano más político que el ICM y orientado hacia la juventud (sus miembros son menores de 35 años). 
dos corrientes del movimiento hip hop: el rap underground, que buscaba negociar favorablemente con el Estado, demandando completar ciertos ideales, objetivos y valores que la revolución prometió; y el rap comercial, que seguía las fuerzas transnacionales y evocaba medios alternativos para sobrevivir, como el jineterismo y el consumismo. ${ }^{6}$

Amenaza, grupo precursor de Orishas y pionero en la evolución del rap en Cuba, fue considerado underground.? Sin embargo, a Orishas se le categorizó como rap comercial, ya que, además de seguir las fuerzas transnacionales, incorporaba ritmos populares cubanos para ganar, según algunos raperos y analistas musicales, mayor aceptación fuera de la isla, alcanzar "autenticidad" y ser rentables comercialmente. Los grupos de rap underground muchas veces mostraban hostilidad hacia los grupos comerciales, reafirmándose en la decisión de que ellos, como grupos underground, no iban a hacer lo que las disqueras extranjeras les exigieran (sobre todo en cuanto a fusionar el rap "puro" con el son, la salsa o la timba, entre otros géneros). Fernandes (2003) explica que los raperos que se denominaban underground tampoco soportaban la celebración del consumismo en las líricas de bandas como Orishas, pues lo consideraban la interferencia de las casas disqueras y su interés de vender a Cuba a las audiencias "occidentales" por medio de estereotipos como el ron,

${ }^{6}$ Para un estudio etnográfico reciente y actualizado del panorama del rap y el reguetón en La Habana y que presenta, además, una mirada encontrada a la visión racializada del rap de Fernandes, véase el libro Buena Vista in the Club: Rap, reggaetón, and Revolution in Havana, de Geoffrey Baker (2011).

7 En este sentido desarrollo indirectamente a lo largo del artículo la relación y una aparente sinonimia entre la clasificación de rap "underground" y "político" versus el "comercial". Algunos ejemplos de grupos underground contemporáneos a Orishas fueron Obsesión, Primera Base, Los Paisanos, Anónimo Consejo, Alto Voltaje, Triple A, Corte, $100 \%$ Original y Explosión Suprema. Muchos de estos grupo ya no existen o sus integrantes viven fuera de Cuba y practican otros géneros, como el cubatón. Hoy en día el rap cubano podría catalogarse entre los raperos institucionalizados y los no institucionalizados; para muchos practicantes esto define el rap cubano comercial (perteneciendo al catálogo de la Agencia Cubana de Rap) o el rap cubano underground (independientes). Esto es aún más relevante ahora que muchos jóvenes tienen acceso a estudios de grabación y producción dentro de la sociedad civil y que no dependen de las instituciones gubernamentales para grabar y viajar. 
el tabaco y la mulata. Por tal razón se estableció que Orishas llegó a perder su vínculo con el movimiento de hip hop cubano.

En lo personal, no tengo problemas con llamar a Orishas grupo de rap comercial, pues lo confirman su éxito en Cuba, Europa y América, entre otros lugares, y la naturaleza de sus líricas. Empero, coincido con Fernandes al apuntar que la banda también combatió los estándares morales convencionales, creó nuevos espacios de expresión tanto en Cuba como en otros países y promovió estrategias de resistencia y sobrevivencia alterna que se basaban, en parte, en el jineterismo y el consumismo.

Cabe decir que a lo largo de la década de los noventa las casas disqueras extranjeras no fueron las únicas que buscaron manipular las expresiones musicales populares, como la timba y el rap, pues el propio Estado cubano se encargó de relacionarse también con los raperos cubanos, en especial con los underground. Así, el gobierno negoció con el movimiento rapero, que tanta fuerza juvenil y política poseía, y apoyó a los grupos de rap que mantuvieron en sus canciones una orientación política favorable. Desde 1998 los grupos de rap se organizaron en un sistema de empresas bajo el Ministerio de Cultura. Desde entonces se expresaba que los grupos fueron perdiendo autonomía, al tener que pedir permiso para muchas de sus actividades y grabaciones, y por reproducir una relación paternal con la política cultural oficial.

Lo significativo es que ni las instituciones oficiales del gobierno ni la industria pudieron apropiarse o manipular por completo a Orishas. Por un lado, el gobierno se relacionó con el grupo, pues le favorecían los fondos extranjeros que traían las casas disqueras. Y Orishas, aunque se encontraba y producía fuera de Cuba, fue visto como un grupo de "adentro", Ilegando a ser considerado parte de la nueva revolución, según narraron los propios integrantes en su página oficial. Pero, ¿qué revolución? ¿Cuáles fueron, pues, las estrategias que le permitieron a Orishas navegar y cruzar por distintos espacios discursivos de poder aparentemente contradictorios? 


\section{Entre la santería y los estereotipos: estrategias de Orishas para construir su identidad}

Cuba podría ser, quizá, uno de los países que más ha producido músicos y ritmos en el mundo. Tanto la fascinación del extranjero por la cultura y música afrocubanas como su comercialización tienen una larga y compleja historia. Todos los gobiernos cubanos, además, han exhibido y sacado partido económico, de una u otra forma, de la música, los rituales y el arte afrocubanos. Entonces, Orishas no es innovador en ninguno de estos aspectos. Tampoco presenta, aunque la prensa haya querido resaltar lo contrario, una novedad en lo tocante a las mezclas musicales que hizo del rap con ritmos afrocubanos. Díaz Ayala (2003) menciona que grupos como Síntesis y Mezcla, por ejemplo, ya habían fusionado el rock con ritmos afrocubanos, y que otros como sBs habían mezclado, antes que Orishas, el rap con el son y la salsa. Por lo tanto, ¿cómo definir las estrategias y la innovación, si la hay, del proyecto cultural de esta banda?

El intento de definir, construir y representar lo cubano es otra de las constantes en las letras de Orishas; técnica no tan solo ensayada por siglos desde distintas tradiciones expresivas, sino explotada con frecuencia. Playas, mujeres, tabaco, ron, la bandera y la evocación de ciertos barrios marginales son signos que aparecen constantemente en sus líricas. Sin embargo, el elemento emotivo tiene en su discurso un rol fundamental en la construcción de la identidad cubana. En términos musicales, los integrantes de Orishas comentaron que querían darle una identidad única al rap cubano, diferenciarlo del estadounidense, y distinguir la identidad nacional y cultural cubana del resto del orbe. Orishas pretendía marcar la diferencia con su música. Con la mezcla de ritmos, prácticas culturales y discursos aparentemente contradictorios confesaron como grupo que lo que buscaban era que el mundo "entendiera" al pueblo cubano. Orishas expresó que mientras más cubano y más tradicional su rap, mayor era su éxito y mejor la aceptación internacional, y que, aunque introdujeron distintos idiomas en sus canciones y representaciones, 
su lenguaje siempre fue el español, en particular el argot callejero cubano, además de que no les interesaba la manera en que los catalogaran, si comercial o políticamente.

La fórmula musical y cultural alcanzada por Orishas les sirvió muy bien para mercadearse e internacionalizarse, pero también para posicionarse, aunque sea de forma ambigua, con el sector oficial cubano. En relación con la política del Estado, los mensajes de sus canciones eran positivos y políticamente correctos. Aunque ellos manifestaban que no eran políticos, sino músicos, y que no querían mezclar ambas esferas, lo cierto es que sus estrategias les permitieron tomar posiciones ambiguas, a la vez que no se dejaron manipular y pudieron proyectar una propuesta artística sólida.

Sobre la religión, la propuesta de Orishas resulta aún más interesante. Según se desprende de sus presentaciones y entrevistas, los músicos eran practicantes devotos de la santería, aunque no incorporaban con regularidad los toques de santos o ritmos litúrgicos ni el tema de la religión en sus canciones. ${ }^{8}$ Sin embargo, en cada presentación abrían y mostraban reverencias a los orishas, expresando su respeto y agradecimiento, y pidiendo gentilezas. Al utilizar la religión desde el mismo nombre del grupo, muchos les imputaron formar parte de la comercialización de la santería; proceso que se

${ }^{8}$ La presencia de la santería en las letras de la música cubana tiene un larga tradición, así como la mezcla de la música litúrgica con otros ritmos. En los años cuarenta y cincuenta salieron las primeras grabaciones comerciales de música de santería, con Miguelito Valdés, Celia Cruz y Celina González (Perna, 2005, p. 166). Durante los años ochenta se permitieron numerosas grabaciones de la música litúrgica afrocubana, pero durante la crisis aumentó la cantidad de temas santeros en la música bailable. La mayoría de las bandas más importantes sacaron temas relacionados con esta religión. "En 1989 la orquesta Aragón graba el tema 'Oye sacúdete', después aparece 'Yo voy a pedir pa' ti' de Adalberto Álvarez y su son. En este número los cánticos yorubas se unen, en una parte de la canción, a rap. Además, la Orquesta Revé lanza en 1993 el tema 'Papá Eleguá' y los Van Van, 'Soy todo', poema de Eloy Machado cuya versión musical se ha convertido en himno de la santería en Cuba" (Díaz Ayala, 2003, p. 393). Hay que recordar también la versión de "Que viva Changó", de NG La Banda, en 1990. Sobre la mezcla de diferentes géneros con ritmos litúrgicos no se debe olvidar que en 1991 el grupo Síntesis, Carlos Alfonso, graba el LP Ancestros I, en el que se realiza una interesante fusión de elementos litúrgicos afrocubanos y rock. De acuerdo con Díaz Ayala (2003, p. 393), esto representa una doble liberación, primero por la vertiente de lo religioso, pero también por la admisión del rock en la música que se hace desde Cuba. 
había agudizado drásticamente durante el Periodo Especial, hasta el punto en que el gobierno también llegó a apoyar y promover el turismo santero.

Orishas -dioses del panteón yoruba, divinidades de la santería- es un nombre poco modesto (aunque jugar con la exaltación y el poder del individuo es precisamente una característica del rap), empero, no enfatiza en el individuo sino en una colectividad. En entrevista con Fernando F. Garayoa (1999), los integrantes explicaron que el nombre del grupo no quiere decir que ellos pretendían ser dioses, más bien lo que buscaban era que en donde quiera que se encontrasen y hubiese un cubano, este pudiera identificarse con ellos. Los integrantes de la banda en un principio solían presentarse en escena vestidos de blanco y con collares, acto ni original ni humilde, pero fueron dejando de hacerlo porque entendieron que no debían convertir la religión en marketing.

La incorporación de este elemento cultural refleja, entonces, un significado fundamental para entender la estrategia cultural del grupo. Los miembros de la banda han comentado parte de la importancia de la religión para Cuba al expresar que "lo bonito de mi religión es que no obliga a nada", y que vestían de blanco y llevaban collares no como producto comercial, sino como una forma de defender sus raíces, de demostrar la espiritualidad cubana y la cultura de la isla. Perna (2005, p. 162) establece que la presencia de la santería en la música bailable (el autor estudia la timba, pero bien podría estar hablando del rap) permite manifestar continuidad con el pasado y solicitar identificación cultural. La santería marca la identidad cubana de forma especial y resurge durante el Periodo Especial. Los timberos la llevaron al escenario, y Orishas continuó con esa tradición, aunque este hecho haya sido criticado como pérdida de autenticidad de la cultura cubana o corrupción alentada por la economía global. Lo cierto es que la presencia de la santería forma parte de una de las estrategias de construcción y negociación de la identidad más significativas que Ilevó a cabo Orishas y cuyo valor radica en varios puntos que mencionaré a continuación. 
Primero, en América, la esencia de la santería es sincrética, significa camuflaje, escondiendo en su trayectoria una larga historia de resistencia. En cuanto emisarios del Dios Olodumare, los orishas se ocultaron detrás de la fachada del catolicismo y de sus santos, y siguen presentes en el pueblo cubano. De modo que representa una práctica viva que puede considerarse la religión nacional de Cuba; es también una religión flexible, pragmática, multifacética, que se constituye como factor social estabilizador importante. Además, ha sobrevivido en la clandestinidad; es, al igual que muchas prácticas musicales, underground. Asimismo, fortalece la identidad afrocubana en cuanto grupo social y cultural distinto. Como la música popular, la santería tiene un rol autónomo fuera de la esfera política o pública.

Para muchos cubanos, la explosión y el uso de la santería durante la crisis no se debió únicamente al cambio en la actitud legal por parte del gobierno y por el turismo religioso sino también a las dificultades materiales y espirituales que vivió el pueblo en general durante esa época. La religión ayudó a muchos a sobrevivir, proveyendo apoyo, fuerza y esperanza. La emergencia de la santería en la timba, y en Orishas, no solo representó una reafirmación de lo afrocubano sino que ayudó a mercadearlo y a constituirse como una fuente de ingreso. Parte de la estrategia de la santería, de sus coqueteos, negociaciones y subversiones respecto a los discursos de poder tuvo que ver con su explotación durante la crisis, ya que se convirtió en un negocio muy lucrativo, que se conectaba con el turismo.

La santería y la música se adaptan y se transforman, pues son antiesencialistas; además, tienen la capacidad de apropiarse eclécticamente de otros discursos. Sin prejuicios ni complejos, ambas prácticas poseen la capacidad de mezclar y liberar tensiones sociales. Perna (2005, p. 189) comenta que lo que a primera vista puede ser considerado una forma de comercialización, desde una perspectiva no esencialista puede tomar un significado distinto y ser leído como una práctica cultural que es significativa no por su cercanía literal 
a un modelo y a un origen, sino porque simplemente la audiencia cubana se identifica y acepta la existencia de continuidad de la timba, la religión negra y la tradición cultural.

El despliegue de ritmos, melodías y temas que muestra el proyecto musical de Orishas (y que merece un estudio aparte) debiera entenderse no como un fenómeno exótico o nostálgico, sino como un intento de la identidad afrocubana de arraigarse a su pasado e incorporar la cultura callejera y la religión en una versión posmoderna. Las tradiciones de la santería requieren un conocimiento específico y no público por medio de ritos, canciones y lenguaje. Como estrategia, Orishas podía esconder frente al escucha o receptor extranjero la realidad o el significado primordial de su música; solo los cubanos pudieron haber entendido ciertos mensajes y códigos. Por todo lo mencionado, la incorporación de este elemento cultural en el proyecto musical refleja, entonces, un significado esencial para comprender la estrategia cultural del grupo.

\section{A modo de conclusión}

Nueva trova, timba y rap son tres prácticas musicales diferentes que han descrito, simbolizado, expresado y pensado la realidad cubana. Se dice que la nueva trova "reflexiona" sobre los imperativos de la realidad, que no tan solo los "comenta", como lo hacen la timba o el rap. Timba y rap, al surgir principalmente de sectores sociales y étnicos distintos de los de la nueva trova, además de responder a un momento histórico diferente, se expresaron en primera instancia con otros códigos y navegaron por otros canales. Sin embargo, las dinámicas de la timba y el rap se asemejan en varios aspectos relevantes. La timba, como el rap de Orishas, a veces le canta al turista, pues lo considera un recurso económico, canal de comunicación con el mundo exterior. Ambos fenómenos musicales, además, no utilizan el lenguaje poético de la trova sino el callejero (aunque en ocasiones sean muy poéticos). Tampoco idealizan la revolución, sino que hablan de la realidad del barrio con un lenguaje retante 
y polémico (en el caso de la timba, mucho más sexual), con referencias a la prostitución, el racismo, la santería y la exaltación del dinero. Tanto la timba como el rap han irritado a los nacionalistas culturales "puristas". En ambos, asimismo, el performance, lo visual, la vestimenta, el carisma individual, el sex-appeal y los movimientos escénicos son importantes para transmitir sus mensajes. Estos músicos -en el caso del rap me refiero solo a Orishas- se convirtieron en el símbolo del nuevo artista popular que se articula en lo moderno, en las aspiraciones y los deseos de los jóvenes urbanos. En relación con las fusiones, la timba y el rap "comercial" se mezclaron con diversos géneros tanto autóctonos como de otros países. Según Perna, esta mezcla entre vieja y moderna hace que la timba (incluyo el rap) se proyecte sin fronteras físicas, culturales o nacionales.

La timba y el rap cubano convergen en un espacio contradictorio, que está formado por pero a la vez se resiste al consumismo capitalista. Además, coexisten en sus discursos tanto el nacionalismo "negro" o "afro" como las estrategias de consumo, según ha identificado Fernandes al hablar del hip hop en Cuba. Fernandes ha explorado las maneras en que los jóvenes afrocubanos se apropian de los imaginarios transnacionales con el fin de enmarcar demandas políticas y estrategias locales. Esta estrategia la utiliza Orishas, y de ahí surge, en parte (pues he obviado por completo la riqueza musical y lírica de este grupo), el valor y el éxito de la agrupación. Orishas pudo resistir algunos aspectos de coaptación de las esferas de poder político gracias a su participación en la red transnacional y la industria musical global. A través de su música, Orishas pudo negociar con algunas instituciones oficiales y construir estrategias de sobrevivencia en las circunstancias económicas difíciles (sobre todo las del Periodo Especial). Las redes del rap transnacional facilitaron al grupo contestar a las jerarquías raciales, demandar justicia y expresar narraciones alternas, a la vez que propusieron ambiguamente al jineterismo y el consumismo como alternativas de sobrevivencia. 
En fin, Orishas combatió y se burló de la ideología conservadora en la que se basaba la moralidad "oficial" cubana, construyéndose también como producto mercadeable.

Por último, coincido con Fernandes en establecer que el rap -e incluyo aquí el proyecto de Orishas- puede reforzar la hegemonía de las naciones-estados poscoloniales en la actualidad. El rap cubano demuestra que el gobierno puede usar esa energía para crear una imagen de Cuba en cuanto nación mezclada racialmente con raíces africanas, para cohesionar con mayor fuerza la nacionalidad, como lo ha hecho antes usando otras prácticas culturales. De tal modo, esta práctica musical cuestiona la teoría de la globalización en la que el crecimiento de flujos culturales transnacionales basados en imaginarios sociales y culturales alternos como la raza no van con un Estado-nación ligado al territorio, como el caso de Cuba, pues esta teoría ignora las alianzas que se dan entre cuerpos nacionales y transnacionales (Fernandes, 2003, p. 597). Orishas, mientras tejía redes con el movimiento de hip hop en Estados Unidos y otras partes del mundo (fundamentándose en asuntos de raza y marginalidad que trascendían afiliaciones nacionales), generó simultáneamente una crítica al capitalismo global y al propio gobierno oficial cubano.

\section{Fuentes citadas}

Acosta Llerena, O. (s. f.). El kilo de Orishas. Recuperado de http://www. habanaradio.cu/modules/mysections/singlefile.php?lid=49

Agencia EFE (s. f.). Orishas regresa con todos los kilos. Recuperado de http://www.esmas.com/espectaculos/musica/423921.html

Baker, G. (2011). Buena Vista in the Club: Rap, Reggaetón, and Revolution in Havana. Durham: Duke University Press.

Borges Triana, J. (s. f.a). Aquí no hay vida para los mareos. La Jiribilla. Recuperado de http://www.lajiribilla.cu/2001/n15_agosto/432_15. html 
Borges Triana, J. (s. f.b). Música de lo cotidiano. La Jiribilla. Recuperado de http://www.lajiribilla.cu/2001/n15_agosto/432_15.html

Borges Triana, J. (s. f.c). Se abren los caminos del rap. La Jiribilla. Recuperado de http://www.lajiribilla.cu/2001/n15_agosto/432_15.html

Borges Triana, J. (s. f.d). Obsesión rapera. La Jiribilla. Recuperado de http:// www.lajiribilla.cu/2001/n15_agosto/432_15.html

Bustamante, B. y Reitich, E. (s. f.). Talento y Ashé. Recuperado de http:// www.espanol.music.yahoo.com/especiales/orishas

Correa, C. (s. f.). Roldán González, líder de la banda de hip hop cubana Orishas: "Todos somos castristas". El Mostrador. Recuperado de http://www.lahaine.org/musica/roldan_castrista.html

Díaz, A. L. (s. f.). Rap cubano: ¿quién tiró la tiza? Cubanet. Recuperado de http://www.cubanet.org/CNews/y02/oct02/04a8.html

Díaz Ayala, C. (2003). Música cubana: del areyto al rap cubano (4⿳亠丷厂 ed.). San Juan: Fundación Musicalia.

Eklund Koza, J. (1999). Rap Music: The Cultural Politics of Official Representation. En C. McCarthy y G. Hudak (Eds.), Sound Identities. Popular Music and the Cultural Politics of Education (pp. 65-92). Nueva York: Peter Lang.

Fernandes, S. (otoño, 2003). Fear of a Black Nation: Local Rappers, Transnacional Crossings, and State Power in Contemporary Cuba. Anthropological Quarterly, 76(4), 575-608.

Fernández Díaz, A. (2001). Rap cubano: poesía urbana o la nueva trova de los noventa. El Caimán Barbudo, 33(296), 4-14.

Fernández Díaz, A. (s. f.a). Orishas (Cuba): "El rap es una revolución urbana". La Jiribilla. Recuperado de http://www.lahaine.org/musica/ orishas_urbana.html

Fernández Díaz, A. (s. f.b). Orishas: rap que nace de la diferencia. Recuperado de http://www.orishasthebest.com/Secciones/Entrevistas/Entrevista_Ariel_Fernández.pdf

Fernández Díaz, A. (s. f.c). ¿Poesía urbana o la nueva trova de los noventa? La Jiribilla. Recuperado de http://www.lajiribilla.cu/2001/ n15_agosto/414_15.html

Fernández Díaz, A. (13 de noviembre de 2002). Los futuros inmediatos del hip hop cubano. Juventud Rebelde-La Ventana. Recuperado de 
http://www.morfonet.cl/secciones/musicos /013.html

Garayoa, F. F. (22 de diciembre de 1999). Cuba, a ritmo de rap. Diario de Noticias. Recuperado de http://www.afrojazz.com/Music_Styles/ Rock__Rap/ORISHAS/orishas.html [2013, 9 de mayo].

García, J. J. (30 de mayo de 2005). Orishas: "En Cuba el rap era la música del enemigo". BuscaMúsica. Recuperado de http://www.buscamusica.org/ezine/entrevista/orishas.htm

Hernández Baguer, G. y Casanella Cué, L. (12-18 de noviembre de 2005). Hora de abrir los ojos... El rap cubano existe. La Jiribilla, IV. Recuperado de http://www.lajiribilla.cu/2002/n67_agosto/1608_.html\#mark6

Martín, F. (15 de febrero de 2005). El grupo cubano Orishas edita un disco Ileno de compromiso social. El País. Recuperado de http//www. rebelion.org /noticia.php?lid=11388

Mendoza, L. (21 de agosto de 2003). Rap cubano: una visión diferente y desperjuiciada. World Data Service. Recuperado de http://www. wdrc.cubaresearch.info

Otero Garabís, J. (2000). Contrapuenteos y síntesis culturales en la Cuba revolucionaria. En Nación y ritmo: "descargas" desde el Caribe (pp. 165-221). San Juan: Ediciones Callejón.

Página oficial del grupo Orishas (s. f.). Recuperado de http://www.orishasthebest.com

Paneque Brizuela, A. (s. f.). Is Rap Occupying its Rightful Place in Life? Movimiento, La Revista Cubana de Hip Hop, 3. Recuperado de http://www.walterlippmann.com/docs023.html

Perna, V. (2005). Timba: The Sound of the Cuban Crisis. Londres: Ashgate.

\section{Discografía}

Orishas (2000). A lo cubano. Universal y Surco Records.

Orishas (2002). Emigrante. Surco Records, J. V. y EMI Music España.

Orishas (2005). El kilo. EMı Music España 